\title{
Domain Knowledge and Team Creativity: A Typological View
}

\begin{abstract}
Wisal Ahmad ${ }^{1}$, Mark Stufhaut ${ }^{2}$, Nancy Johnson ${ }^{3}$
Abstract

This study presents a typological view of domain knowledge and creativity from teamwork perspective. With this in mind, the study reviews the literature on team members' collaboration, role centrality and its implications for team creativity. The study proposes a continuum of team creativity and different combinations of domain expertise possessed by the team members such that teams with more balanced domain expertise are more likely to produce more creative outcome than a team where its members consist imbalanced domain expertise. The study presents interesting avenues for future researchers.
\end{abstract}

Keywords: Collaboration, Creative Process, Teamwork, Domain Knowledge.

\section{Introduction}

Creativity research has entered a stage where creative outcome is viewed as the product of teamwork rather individual contribution of team members (Chung, 2009; Rio Perez, 2006). Team members having different domain expertise contribute to the team knowledge relationship system that leads to greater team interactions (Quinn, 2000; Wasko \& Faraj, 2005) and hence a novel outcome that is not usually possible with single person knowledge. The team interaction helps its members to not only contribute towards the team goal from different domains but also triggers individual team members' memory nodes to generate multiple associations about a concept. Thus teamwork has consistently been linked with greater creativity (Kilgour, 2006).

Recent researchers however believe that a team suffering from issues such as role-centrality does not produce a creative outcome due to imbalanced domain knowledge of team and hence unidirectional interaction in the team (Ahmad, 2015). Since the team members' interaction depends on the level of team members' domain expertise (Wasko \& Faraj, 2005), it can be argued that a team having a differing level of domain expertise will have different level of team interactivity and hence different creative outcome. More precisely, creative team with a more balanced domain expertise of its members is more likely to have greater and balanced interaction among its members as compared to a team where one or two members have greater domain

1 Assistant Professor, Institute of Management Sciences, KUST. Email: wisalkust@hotmail.com

2 Associate Professor, Gatton College of Business, University of Kentucky. Email: mark.stuhlfaut@ uky.edu

3 Associate Professor, Gatton College of Business, University of Kentucky. Email: nbj@uky.edu 
competency but others have not. In such a scenario, what has been termed by researchers (Ahmad, 2015), the issue of role-centrality will arise and the team outcome will mainly reflect the contribution of few team members who have predominantly greater domain expertise. In such a situation, the interaction will be mainly centered towards the senior most members who will act as the decision making authority. Research has found that such teams are least interactive such that communication flows from the most senior towards the junior member and the final decision is not based on objective and logical grounds rather rests with the senior member (Ahmad, 2015). This is so because senior members are widely regarded for their lifelong experiences. However, this is a mean of high cost to the organization in terms of innovations and hence failure to gain greater competitive advantage. Hence, this study addresses the issue of domain knowledge configuration in creative teams in order to fully understand the qualities of creative team that better produces a greater creative outcome. This research primarily addresses the question "how different teams with varying level of domain knowledge affect the team level creativity? To address this primary question, the research answers the following sub-questions. (i) Does high and balanced domain knowledge of team members produce the highest level of creative outcome compared to other teams? (ii) Does a team having its members with high but moderately imbalanced domain knowledge produce greater creative outcome than a team having its members possess low but highly balanced domain knowledge?

\section{Literature Review}

The domain knowledge has been stated as the major driver of creativity (Amabilie, 1995; Kilgour, 2006). Greater domain knowledge provides greater mental resources to a creative person and facilitates him in search for alternatives and forming different associations in order to find a novel solution to a given problem (Amabile \& Khaire, 2008; Zhang \& Bartol, 2010). Recent shift in creativity research looking at creativity as a group effort (Chung, 2009; Johar, Holbrook \& Stern, 2001; Rio Perez, 2006) rather the outcome of a single person. Chung (2009) further necessitates it to look at the domain knowledge configuration of a team that could produce a creative outcome rather a routine solution to a given problem. This is mainly due to the reason that although domain knowledge of team members plays a detrimental role in the production of a novel outcome, however, recent research work also provides sufficient evidence which states that a more creative team is one where besides other issues, the team members possess an equal and balanced domain knowledge (Ahmad, 2015). Further, Ahmad (2015) also found that in other least creative teams, there existed a serious issue of role-centrality where the most senior team member dominated the entire collaborative functions including communication, goal sharing and many other interactive activities in team. One of the major reasons for role centrality issue in 
creative teams has been found to be the greater domain expertise of a team members compared to other team members (Ahmad, 2015). Hence it implies that domain competence and expertise of team members should be well balanced so that all team members should equally contribute from their respective areas of expertise towards the team goal. Only then a team can be able to integrate and reap the benefits of team diverse expertise.

In real practice, organizations particularly those where creativity and innovation is a central matter such as computer and other technology firms, advertising industry etc. tasks are performed in teams. The composition of these working teams however vary in terms of team members' domain expertise due to greater turnover among the team members for better offers by other such companies. Thus, a team may be such where majority of team members possess high domain expertise with a few members who are in the initial stage of their career and hence have less domain expertise. Parallel with the same but opposite line, a team may also be composed of members with one or a few members possessing high domain expertise with majority of other team members having less domain expertise. Such teams have been termed as "imbalanced team" (Ahmad, 2015).

Extensive review of literature in various research areas including knowledge management (Massey, Montoya-Weiss, \& O’Driscoll, 2002), creativity and innovation (Gilson, Mathieu, Shalley, \& Ruddy, 2005), team diversity (Somech, 2006; Jehn, Northcraft, \& Neale, 1999) and decision making in groups (Brodbeck, Kerschreiter, Mojzisch, \& Schulz-Hardt, 2007; Lu, Yuan, \& McLeod, 2012) guides us in this regard with two shared assumptions; First, that novel and creative idea generation is contingent upon an individual access to diverse knowledge pool (Homan, Van Knippenberg, Van Kleef, \& De Dreu, 2007; Polzer, Milton, \& Swann, 2002; Gibson \& Gibbs, 2006; Hambrick, Cho, \& Chen, 1996) and second, that there must be sufficient knowledge sharing among team members so that diverse expertise could be cross-fertilized for knowledge generation and creative outcome to occur (Gong, Kim, Zhu, \& Lee, 2013; Hargadon \& Bechky, 2006; Paulus, 2008; Srivastava, Bartol, \& Locke, 2006; Tiwana \& McLean, 2005). This all reflect that team members should have high but similar level of domain expertise in order to avoid role-centrality by one team member possessing substantially higher domain knowledge and which hinders the team interaction process, the knowledge sharing process in a team and hence the occurrence of creative outcome by a team (Leenders, van Engelen \& Kratzer, 2003; Paulus \& Yang, 2000; Taggar, 2002; Freeman, 1979). The role centrality theory as discussed in this study and which served as one of the main base for developing domain expertise and team creativity typology in this study is also supported by various team work researchers (De Dreu 2007; Majchrzak, More, \& Faraj, 2012; Kratzer, Leenders 
\& van Engelen, 2005). Team role-centrality refers to the extent to which interactions in a team are concentrated in one or few individuals rather than distributed equally among all members (Mehra, Kilduff \& Brass, 2001; Sparrowe, Liden, Wayne \& Kraimer, 2001; Costenbader \&Valente, 2003; Perry-Smith \& Shalley, 2003). According to Reagans and McEvily (2003), high centrality in teams decreases team members' inter-connectedness, harms team cohesiveness and discourages flow of information within the teams. De Dreu (2007) and Majchrzak et al. (2012) go beyond the mere knowledge sharing in teams and argue that team members should not only indulge in knowledge sharing but also the sharing of knowledge should be elaborative enough for the recipient to fully comprehend and digest (De Dreu 2007; Majchrzak et al., 2012). This will further enhance the individual team members' domain expertise (Ahmad, 2015) as well as synergize the individual team members' creativity (Woodman, Sawyer \& Griffin, 1993; Amabile, 1997) leading to greater mental resources, large number of associations which will ultimately result in greater creative outcome (Keller, 1993).

Thus, building on domain knowledge (Homan et al., 2007; Gibson \& Gibbs, 2006) as well as role centrality theory (Mehra et al., 2001; Perry-Smith \& Shalley, 2003; Ahmad, 2015), teams in any of such imbalanced situations will least likely produce a creative outcome due to either greater role centrality in team, less domain knowledge and less integration of team members' knowledge integration respectively. More particularly, teams with majority of its members possessing less domain competency and one or few team members having greater domain expertise will suffer from less integration of team members' knowledge as well as greater centrality of the team affairs by one or two members who are more senior and possess greater domain knowledge. Thus its creative outcome will be the reflection of only one or two of its members without accommodating the creative efforts of other team members. This is so because teams with the majority of its members possessing less domain expertise with major role of highly experienced team member has been found to be less interactive where communication is unidirectional that flows only from the senior member towards other members possessing very less domain expertise (Ahmad, 2015). Similarly, a team made up of more experts and few members in initial stage of their career (less domain knowledge), though the degree of creativity will improve compared to the earlier one due to greater domain expertise and hence greater interaction among the respective team members, however such a team will again overlook the team member being a novice and hence having less domain knowledge.

As far as teams having its members possess low but equal domain knowledge is concerned, it is more likely that the team members will freely collaborate with high degree interaction in all phases of creative outcome development since the team will not be dominated by a single team member and the outcome will reflect the contri- 
bution of all team members. However, due to less expertise, the degree of creative outcome of such a team will be less than a team where all members have high and balanced domain knowledge. Further, such a team will also more likely produce comparatively a less creative outcome in comparison to team where more of its members have high domain knowledge with few members in the initial stage of their career. This is for the reason that although a team being balanced in its domain knowledge will have higher interaction level, but the low domain expertise of its members will not make its members capable to search a novel solution from their past experiences as compared to a team with more experts in their respective domain and few members in the initial stage of their career who will be in a better position to dig into a search of more creative idea. The comparison of a creative team dominated by one or few expert team members and another team having low, but balanced domain expertise by all its members is a bit tricky one. This study synthesis that both domain expertise as well as balance of team members' domain expertise is necessary for creative interactions among the team members and hence provides a synergy of knowledge that produces creative outcome. When a team is dominated by one of the most senior member, he will be respected for whatever he suggests and as such the decision will be made not on the basis of logical and critical discussion but by the willingness of senior most creative in the team. Moreover, such a team member has been found to remain a central figure in all team affairs such that all communication comes and goes towards him (Ahmad, 2015). The outcome developed by such a team is also less creative compared to teams where all interactive activities prevails (Ahmad, 2015). On the other hand, if team members are having though less but balanced domain knowledge will more likely indulge in interactions, critical and logical discussion revolving the objective of the team and the team decision will reflect objectivity rather subjectivity from a single team member. Further, though the less domain expertise may not facilitate a team member to cross his domain of expertise, but it is the beauty of collaboration and high level of interaction that helps individual team members to reach to the level of imagination that could have been difficult to reach alone (Schrage, 1995; Johar, Holbrook, \& Stern, 2001). Thus, it is also hypothesized that such a team will comparatively indulge in greater interaction and will produce relatively greater creative outcome than a team dominated by a single most experienced and knowledgeable team member.

For ease and greater understanding, the different configuration of teams representing varying levels of domain expertise and team composition in terms of their domain knowledge as discussed above are represented by names such that a team having all its members possessing high and balanced domain expertise is termed as team A. Team A has been discussed above as most creative in terms of its outcome followed by Team B in which the majority of team members have high and moder- 
ately balanced domain expertise. Team $\mathrm{B}$ has been argued to have a greater creative outcome than all teams except Team A. Team C is having all its members possess lesser domain knowledge; but is highly balanced and its creative outcome will rank third in creativity. More simply, the chronological order of team names represents the level of the respective team creativity. In team $\mathrm{D}$, one of the members has the high domain knowledge; but highly imbalanced in terms of domain expertise of other team members. Team E consists of members with less domain knowledge and moderately imbalanced in terms of domain knowledge possessed by its members followed by Team F where all team members have less domain knowledge and highly imbalanced. The team configuration with varying levels of domain knowledge and team creativity is shown in a matrix form in table 1 below.

Table 1: Typology of Team Configuration, Team Members' Domain Knowledge and Team Creativity

\begin{tabular}{|c|c|c|c|}
\hline $\begin{array}{c}\text { Level of Domain } \\
\text { Knowledge }\end{array}$ & \multicolumn{3}{|c|}{ Team Configuration by Domain Knowledge } \\
\hline & $\begin{array}{c}\text { Highly Balanced } \\
\text { Team }\end{array}$ & $\begin{array}{c}\text { Moderately Balanced } \\
\text { Team }\end{array}$ & Low Balanced Team \\
\hline $\begin{array}{c}\text { High Domain } \\
\text { Knowledge }\end{array}$ & $\begin{array}{c}\text { TEAM -A } \\
\text { (All Team Members } \\
\text { with High and } \\
\text { Equal Domain } \\
\text { Knowledge) }\end{array}$ & $\begin{array}{c}\text { TEAM -B } \\
\text { (Majority of Team Mem- } \\
\text { bers with high domain } \\
\text { Knowledge and One with } \\
\text { Novice Team Member) }\end{array}$ & $\begin{array}{c}\text { TEAM -D } \\
\text { (ONLY One of the team } \\
\text { main knowledge and Others } \\
\text { being Novice in the field) }\end{array}$ \\
\hline $\begin{array}{c}\text { Low Domain } \\
\text { Knowledge }\end{array}$ & $\begin{array}{c}\text { TEAM -C } \\
\text { (All Team Members } \\
\text { with Low BUT } \\
\text { Equal Domain } \\
\text { Knowledge) }\end{array}$ & $\begin{array}{c}\text { TEAM -E } \\
\text { (All Team Members with } \\
\text { Low domain knowledge } \\
\text { with a slight difference in } \\
\text { their domain Knowledge) }\end{array}$ & $\begin{array}{c}\text { TEAM -F } \\
\text { (All Team Members with } \\
\text { Low domain knowledge } \\
\text { BUteater difference of } \\
\text { Domain Knowledge) }\end{array}$ \\
\hline
\end{tabular}

\subsection{Hypotheses}

The above section discussed the different configuration of teams in the light of varying degree of team members' domain knowledge. This was mainly based on the theory of role centrality (Ahmad, 2015) and domain knowledge of each team member (Sosa, 2011; Kilgour, 2006). As argued in the above section, teams with its members possessing different degree of domain expertise are more likely to suffer from role-centrality issue and hence indulge in an imbalanced interaction that would lead to different level of creative outcome by the respective teams. Based on this discussion, the following hypotheses are deduced:

$\mathrm{H}_{1}$ : Team A will produce significantly greater Creative Outcome than all other Teams. 
$\mathrm{H}_{2}$ : Team B will produce significantly greater Creative Outcome than all other Teams except Team A.

$\mathrm{H}_{3}$ : Team $\mathrm{C}$ will produce significantly greater Creative Outcome than all other Teams except Team A and B.

$\mathrm{H}_{4}$ : Team $\mathrm{D}$ will produce significantly greater Creative Outcome than all other Teams except Team A, B and C.

$\mathrm{H}_{5}$ : Team E will produce significantly greater Creative Outcome than Team $\mathrm{F}$ except Team A, B and C and D.

$\mathrm{H}_{6}$ : Team F will produce significantly least Creative Outcome than all other Teams.

\section{Limitations and Future Recommendations}

Despite the much significance of the study, the present study has a few limitations and as such opens up new and interesting avenues for future researchers. The study is more of a conceptual nature and presents a new typology on domain knowledge and team creativity which in fact makes it a unique work. Hence, the hypotheses developed in this study may be tested empirically in order to establish its validity. It can be more suitably tested in real organizations settings such as high tech firms, advertising agencies etc. Further, a cross cultural perspective of team interactions, domain knowledge and creativity can also be empirically investigated particularly in developed countries in order to know how creativity in teams can be accelerated. Further, the same hypotheses can be tested to see how much different organizations in any developed country practicing teamwork are creative.

\section{Conclusion}

Creativity research has now shifted from an individualistic perspective to a team based approach believing that team members having different expertise lead to synergy and hence a more creative outcome than an individualistic creativity (Chung, 2009; Rio Perez, 2006). However, recent researchers believe that teams suffering from issues such as role-centrality does not produce a creative outcome due to imbalanced domain knowledge of team and hence unidirectional interaction in the team (Ahmad, 2015). Since the interaction among team members have been stated to depend upon team members' level of domain expertise (Wasko \& Faraj, 2005), it can be well argued that a team having a differing level of domain knowledge will have different level of team interactivity and hence different creative outcome. More precisely, creative team with a more balanced domain expertise of its members is more likely to have greater and balanced interaction among its members as compared to a team where one or two 
members have greater domain competency but others have not. This has been termed as teams with imbalanced domain expertise where interaction is usually unidirectional coming from and the most senior towards the junior member and the final decision is not based on objective and logical grounds rather rests with the senior member (Ahmad, 2015). More precisely, creative team with a more balanced domain expertise of its members is more likely to have greater and balanced interaction compared to the one where team members possess imbalanced domain knowledge.

Overall, this study can be regarded as making much theoretical and practical implications. First, the study focuses on domain knowledge of team members and creativity from a continuum perspective; thus enabling researchers to more clearly understand the nature of teamwork and creativity. Second, this study conceives more creative teams compared to a least creative team by looking into the composition of domain knowledge possessed by its team members.

\section{References}

Ahmad, W. (2015). Understanding the collaborative dynamics of creative team: Implications for creative advertising design. Unpublished Postdoctoral Paper, University of Kentucky, USA.

Amabile, T. M. (1995). Attributions of creativity: What are the consequences? Creativity Research Journal, $8(4), 423-426$.

Amabile, T. M. (1997). Motivating creativity in organizations: On doing what you love and loving what you do. California Management Review, 40(1), 39-59.

Amabilie, T. M., \& Khaire, M. (2008). Creativity and the role of the leader. Harvard Business Review, 86(10), 101-109.

Ang, S. H., Lee, Y. H., \& Leong, S. M. (2007). The Ad creativity cube: Conceptualization and initial validation. Journal of the Academy of Marketing Science, 35(2), 220-232.

Brodbeck, F. C., Kerschreiter, R., Mojzisch, A., \& Schulz-Hardt, S. (2007). Group decision making under conditions of distributed knowledge: The information asymmetries model. Academy of Management Journal, 32(2), 459-479.

Chung, S. E. (2009). Supporting creativity in interdisciplinary teamwork: Examining relationships among individual traits, group characteristics, team process and creative performance in an applied setting. Unpublished Master dissertation. University of Florida.

Costenbader, E., \& Valente, T. W. (2003). The stability of centrality measures when networks are sampled. Social Networks, 25(4), 283-307.

De Dreu, C. K. W. (2007). Cooperative outcome interdependence, task reflexivity, and team effectiveness: A motivated information processing perspective. Journal of Applied Psychology, 92(3), 628-638. 
Freeman, L. C. (1979). Centrality in social networks: Conceptual clarification. Social Networks, 1(3), 215-39.

Gibson, C. B., \& Gibbs, J. L. (2006). Unpacking the concept of virtuality: The effects of geographic dispersion, electronic dependence, dynamic structure, and national diversity on team innovation. Administrative Science Quarterly, 21(3), 451-495.

Gilson, L. L., Mathieu, J. E., Shalley, C. E., \& Ruddy, T. M. (2005). Creativity and standardization: Complementary or conflicting drivers of team effectiveness? Academy of Management Journal, 48(3), 521-531.

Gong, Y., Kim, T. Y., Zhu, J., \& Lee, D. R. (2013). A multilevel model of team goal orientation, information exchange, and creativity. Academy of Management Journal, 56(3), 827-851.

Hambrick, D. C., Cho, T. S., \& Chen, M. J. (1996). The influence of top management team heterogeneity on firms' competitive moves. Administrative Science Quarterly, 41(4), 659-684.

Hargadon, A. B., \& Bechky, B. A. (2006). When collections of creatives become creative collectives: A field study of problem solving at work. Organization Science, 17(4), 484-500.

Homan, A. C., Van Knippenberg, D., Van Kleef, G. A., \& De Dreu, C. K. W. (2007). Bridging faultlines by valuing diversity: Diversity beliefs, information elaboration, and performance in diverse work groups. Journal of Applied Psychology, 92(5), 1189-1199.

Jehn, K. A., Northcraft, G. B., \& Neale, M. A. (1999). Why some differences make a difference: A field study of diversity, conflict, and performance in workgroups. Administrative Science Quarterly, 44(4), 741-463.

Johar, G. V., Holbrook, M. B., \& Stern, B. B. (2001). The role of myth in creative advertising design: Theory, process and outcome. Journal of Advertising, 30(2), 1-25.

Kilgour, A. M. (2006). The creative process: the effects of domain specific knowledge and creative thinking techniques on creativity. Unpublished doctoral dissertation, University of Waikato.

Keller, K. L. (1993). Conceptualizing, measuring, and managing customer-based brand equity. Journal of Marketing, 57(1), 1-22.

Kratzer, J., Leenders, R. T. A. J., \& van Engelen, J. M. L. (2005). Keep virtual R\&D teams creative. Research and Technology Management, 48(1), 13-16.

Leenders, R. T. A. J., van Engelen, J. M. L., \& Kratzer, J. (2003). Virtuality, communication, and new product team creativity: A social network perspective. Journal of Engineering and Technology Management, 20(1-2), 69-92.

Lu, L., Yuan, Y. C., \& McLeod, P. L. (2012). Twenty-five years of hidden profiles in group decision making: A meta-analysis. Personality and Social Psychology Review, 16(1), 54-75.

Majchrzak, A., More, P. H. B., \& Faraj, S. (2012). Transcending knowledge differences in cross-functional 
teams. Organization Science, 23(4), 951-970.

Massey, A. P., Montoya-Weiss, M. M., \& O’Driscoll, T. M. (2002). Knowledge management in pursuit of performance: Insights from Nortel networks. MIS Quarterly, 26(3), 269-289.

Mehra, A., Kilduff, M., \& Brass, D. (2001). the social networks of high and low self-monitors: Implications for workplace performance. Administrative Science Quarterly, 46(2), 121-46.

Paulus, P. B. (2008). Fostering creativity in groups and teams. In J. Zhou \& C. Shalley (Eds.), Handbook of organizational creativity. (pp. 165-188). New York: Lawrence Erlbaum.

Paulus, P. B., \& Yang, H. C. (2000). Idea generation in groups: A basis for creativity in organizations. Organizational Behavior and Human Decision Processes, 82(1), 76-87.

Perry-Smith, J. E., \& Shalley, C. E. (2003). The social side of creativity: A static and dynamic social network perspective. Academy of Management Review, 28(1), 89-106.

Polzer, J. T., Milton, L. P., \& Swann, W. B. J. (2002). Capitalizing on diversity: Interpersonal congruence in small work groups. Administrative Science Quarterly, 47(2), 286-324.

Quinn, F. M. (2000). Reflection and reflective practice. In C. Davies, L. Finlay, \& A. Bullman (Eds.), Changing practice in health and social care. (pp.81-90). London: Sage Publications.

Reagans, R., \& McEvily, B. (2003). Network structure and knowledge transfer: the effects of cohesion and range. Administrative Science Quarterly, 48(3), 240-67.

Rio Perez, J. D. (2006). Research in advertising creativity in the Journal of Advertising (1972-2006). Journal of Advertising, 35(3), 1-14.

Schrage, M. (1995). No more teams! Mastering the dynamics of creative collaboration. New York: Currency Doubleday.

Somech, A. (2006). The effects of leadership style and team process on performance and innovation in functionally heterogeneous teams. Journal of Management, 32(1), 132-157.

Sosa, M. E. (2011). Where do creative interactions come from: The role of tie content and social network. Organization Science, 22(1), 1-21.

Sparrowe, R. T., Liden, R. C., Wayne, S. J., \& Kraimer, M. L. (2001). Social networks and the performance of individuals and groups. Academy of Management Journal, 44(2), 316-25.

Srivastava, A., Bartol, K. M., \& Locke, E. A. (2006). Empowering leadership in management teams: Effects on knowledge sharing, efficacy, and performance. Academy of Management Journal, 49(6), 1239-1251.

Taggar, S. (2002). Individual creativity and group ability to utilize individual creative resources: A multilevel model. Academy of Management Journal, 45(2), 315-330.

Tiwana, A., \& McLean, E. R. (2005). Expertise integration and creativity in information systems development. Journal of Management Information Systems, 22(1), 13-43. 
Wasko, M. M., \& Faraj, S. (2005). Why should I share? Examining social capital and knowledge contribution in electronic networks of practice. MIS Quarterly, 35-57.

Woodman, R. W., Sawyer, J. E., \& Griffin, R. W. (1993). Toward a theory of organizational creativity. Academy of Management Review, 18(2), 293-321.

Zhang, X., \& Bartol, K. M. (2010). Linking empowering leadership and employee creativity: The influence of psychological empowerment, intrinsic motivation, and creative process engagement. Academy of Management Journal, 53(1), 107-128. 
